\title{
Propuesta metodológica para censo de sonoridades y clasificación de los componentes del paisaje sonoro
}

\author{
Santiago Fernández Trejo ${ }^{1 *}$
}

\section{Resumen}

El presente artículo expone una propuesta para el registro y clasificación de la totalidad de elementos encontrados en un paisaje sonoro determinado, que a su vez funcione como punto de partida para investigaciones específicas posteriores. Retoma propuestas teóricas que permiten dirigir cada una de las etapas de trabajo y expone los resultados obtenidos.

\section{Abstract}

This article presents a proposal for the registration and classification of all the elements found in a given sound landscape, which in turn will serve as a starting point for subsequent specific investigations. It takes up theoretical proposals that allow directing each of the work stages and exposes the results obtained.

\section{Palabras Clave}

Censo, Paisaje sonoro, Clasificación.

\section{Keywords}

Census, Soundscape, Classification.

${ }^{1}$ Profesor investigador en el Colegio de Comunicación de la Universidad del Claustro de Sor Juana.

*Autor para correspondencia: sfernandez@elclaustro.edu.mx

\section{Introducción: el trabajo con el sonido y los paisajes sonoros}

Analizar el paisaje sonoro en busca de evidencias de cualquier índole requiere conocer de manera profunda los componentes del mismo. Desde los planteamientos iniciales de Pierre Schafer (1966) en The Tunning of the World, más las aportaciones de Barry Truax, Michel Chion, Ricardo Atienza, Manuel Carles, Cristina Palmese Manuel Rocha y algunos otros ${ }^{1}$, cada uno de acuerdo con sus líneas de investigación; que pasan por la música, la ecología acústica e incluso la arquitectura, han aportado elementos de los cuales podemos echar mano para proponer un análisis con un objetivo específico: censar las sonoridades de los espacios y clasificarlas con el fin de estudiarlas. Una revisión del trabajo realizado hasta ahora no sólo permite reconocer

\footnotetext{
${ }^{1}$ Incluso desde la música electroacústica, asunto importante pero cuyo enfoque no es el de la sonoridad natural de los lugares.
}

propuestas teórico metodológicas sino adaptarlas para el presente proyecto. De la revisión de los trabajos de los siguientes autores se han obtenido los siguientes indicios.

\section{Primera propuesta de clasificación de los sonidos con fines de estudio}

La primera propuesta importante y que incluso ahora mismo representa un recurrente punto de referencia en cuanto a estudios sobre el sonido fue publicada en Francia, en 1966. Schaeffer (1966), reconocido ahora como uno de los creadores de la música concreta, realiza en El tratado de los objetos musicales una propuesta de clasificación tipomorfológica de los objetos sonoros, dentro del contexto de la propia música concreta. A pesar de que la propuesta de organización de los sonidos que propone Schaeffer corresponde únicamente a criterios de la propia tipología y morfología del autor, que no sería válida para los fines que en esta propuesta se pretende 
realizar, sí representa un trabajo importante en el esfuerzo por clasificar, bajo criterios explícitos, a los sonidos. Sin embargo, su orientación tiene que ver más bien con las características acústicas de cada sonido, sin que éstos tengan que relacionarse con otros, como sucede en los paisajes sonoros donde la sucesión de cada unidad sonora realiza la composición de los mismos.

La presente propuesta quiere retomar un registro sonoro y separar cada uno de sus elementos, para ordenarlos de acuerdo a criterios que permitan su estudio con distintos fines, que pueden ir desde su justificación como patrimonio inmaterial al integrar una categoría de huellas sonoras, por ejemplo; o bien clasificar los elementos de un registro para buscar los elementos que deban controlarse, por representar un signo de contaminación acústica. Se puede entender esta propuesta como una base, que pueda ser utilizada como tal, para el trabajo matizado por intereses muy particulares, como la contaminación acústica o la etnografía sonora, por mencionar dos ejemplos.

\section{Censo de sonoridades y clasificación de sus componentes mediante la tipología de la escucha de Pierre Schaeffer}

Una gran cantidad de las actividades humanas producen sonido, de manera voluntaria cuando hablamos, por ejemplo; y quizás de manera involuntaria, cuando utilizamos alguna máquina cuyo fin principal no es el producir sonido, sino algún otro. Pensemos en el caso de una aspiradora: lo que deseamos es que ésta recoja la basura y el polvo, no que produzca sonido, que incluso puede ser molesto. De la misma manera puede resultar fastidioso el sonido que producen los automóviles que transitan por las calles, o el sonido de los aviones en sus rutas de aterrizaje y despegue, por mencionar casos arquetípicos en la Ciudad de México.

El presente texto pasa de dividir a los sonidos de los ruidos, pues busca la observación de la totalidad de los sonidos que ocurren en un lugar público: la calle; bajo un método que pueda ser aplicado a otros lugares y con otros fines, como ya se planteó antes. Para ello, se exponen a continuación las acciones para la realización de un censo del paisaje sonoro de la calle Bolívar, en el Centro Histórico de la Ciudad de México.

El trabajo ha realizado con base en caminatas de registro de paisaje sonoro, con el objeto de enumerar cada uno de los elementos que componen la grabación y clasificarlo de acuerdo con las categorías propuestas para la escucha por Schaeffer. Así se pretende llegar a la propuesta de una clasificación general de elementos de cualquier paisaje sonoro, lo que permitirá realizar trabajo posterior con distintos enfoques, que como se ha mencionado antes, pues la organización de los componentes de un paisaje sonoro pretende apoyar un trabajo posterior, independientemente de los fines que persiga.

\subsection{El paisaje sonoro}

A mitad de la década de los 50 del siglo XX, Schafer (2005) y su grupo de colaboradores iniciaron el World Soundscape Project (WSP) ${ }^{2}$, auspiciados por la Simon Fraiser University, de Vancouver, Canadá. Dicho proyecto giró alrededor de una serie de reflexiones por parte del autor acerca de los entornos sonoros específicos, a los que nombró paisajes sonoros, entendiendo el término como el sonido resultante de cualquier entorno o actividad concreta. El sonido en un estadio de fútbol es su paisaje sonoro, de la misma manera que cualquier otro lugar delimitado ya no en términos de superficie, sino en el alcance de la escucha o registro. En cuanto a la ecología acústica y las dimensiones sonoras que se han perdido, por dejar de existir; ya porque sus orígenes han dejado de existir, o bien porque que han sido cubiertas por otras y no ha quedado registro de esos sonidos o conjuntos de sonidos. En The Tunning of the world, Schafer aclara los pormenores de su propuesta teórica, misma que se retoma para el presente trabajo. La premisa para el término soundscape parte del concepto landscape ${ }^{3}$, aplicado a la cuestión sonora el significado de este último y se destacan ciertos matices:

- A diferencia de la vista, el oído humano no está recortado por un ángulo de visión limitado, pues podemos escuchar prácticamente desde cualquier

\footnotetext{
${ }^{2}$ Barry Truax. (2013). The World Soundscape Project. 2 de julio de 2014 de Simon Fraiser university Sitio web: http: //www.sfu.ca/ truax/ wsp. html

${ }^{3}$ La traducción del término landscape es paisaje y generalmente se usa para referirse a lo visual, Schafer agrega el prefijo sound para aclarar que está refiriéndose al paisaje sonoro, al sonido derivado de las acciones de un lugar o acción determinados.
} 
dirección; por lo tanto, no es necesario ver lo que estamos percibiendo en términos acústicos, y ello podrá ser reconocido o no de acuerdo con el grado de identidad del paisaje sonoro y la familiaridad del escucha con el mismo.

- El paisaje sonoro sólo puede transcurrir en el tiempo, no es posible dejarlo estático, como sucede con las imágenes.

- Toda acción concreta constituye un paisaje sonoro: el sonido derivado de las acciones de un lugar determinado, pero también las transmisiones de radio pueden ser un paisaje sonoro. (Schafer, 1992, p. 12)

A más de lo anterior, el autor aclara las dos grandes dimensiones que existen de paisaje sonoro:

- Paisaje $h i-f i$, son los paisajes más "naturales", los que integran en sus componentes sonidos de la naturaleza o acciones humanas no mediadas por tecnología.

- Paisaje lo-fi, son los paisajes que integran en mayor medida a las máquinas de cualquier tipo. De hecho, el autor plantea en términos temporales dos dimensiones: los paisajes previos a la Revolución Industrial como $h i-f i$ y los posteriores a la misma como lo- $f i^{4}$

\subsubsection{Componentes del paisaje sonoro}

Los componentes que propone Schafer (1977) para los paisajes sonoros son los siguientes:

Tonalidad (keynote): este es el término musical que identifica la tonalidad de la pieza. Los sonidos de fondo que en principio son creados por la naturaleza, según la geografía y el clima; son el sonido del viento, del agua, de los animales, etcétera.

Señales sonoras (sound signals): son los sonidos que se encuentran en el primer plano a los que podemos traducir como señales sonoras en áreas urbanas se representan por sonidos como el tránsito de los automóviles, las instalaciones eléctricas, el tránsito aéreo, etcétera.

\footnotetext{
${ }^{4}$ En The tunning of the world, Murray Shafer separa las sonoridades del mundo en dos grandes grupos; Hi-fi, para referirse a los sonidos de la naturaleza y sus elementos; y Lo-fi, que se refieren a los sonidos de las máquinas de todo tipo. Esta división también se justifica en los sonidos previos y posteriores a la revolución industrial.
}

Las huellas sonoras (soundmarks): son los sonidos característicos de un área en específico; aquellos que adquieren un valor simbólico y afectivo. Son los que pueden identificar a los lugares o acciones, son en analogía con las huellas digitales, las huellas sonoras que hacen que la vida acústica de lugares o acciones sea única y están representados en su carácter natural por géiseres, cascadas y sonidos de ese tipo. En su carácter creado por el hombre pueden ser las fuentes o las campanas de las iglesias o las alarmas de los relojes de ciertos edificios. Es importante aclarar que el término huella sonora se utilizará como indicativo de sonido característico del lugar, sin atribuirle un valor positivo o negativo.

\section{Tipología de la escucha según Pierre Schaeffer y asociación con los componentes del paisaje sonoro}

Ante la necesidad de ordenar un conjunto de sonoridades aparentemente homogéneas como pueden parecer las de las calles, es necesario acentuar la atención a la información que nos dará cada componente de los paisajes sonoros registrados. Cada paisaje es capaz de dar información precisa sobre sus componentes a través de la escucha. Se hace necesario entonces recurrir a una tipología que permita obtener información de cada conjunto de sonidos en todos los aspectos posibles.

Para este trabajo, se ha utilizado la tipología de la escucha propuesta por Pierre Schaeffer en su Tratado de los objetos musicales, en ella describe tres situaciones concretas de las que se puede obtener información distinta y útil para dicha tarea (Schaeffer, 1966, p. 65-70).

Escucha causal: se presenta más ante situaciones no comunes o conocidas, el espectador se concentra en averiguar qué ha causado el sonido. En términos de identidad sonora, los eventos de este tipo se alejan en posibilidades de contribuir a su interpretación, pues implica un esfuerzo por reconocer eventos sonoros de origen desconocido o no reconocido sin esfuerzo, aunque hay sonidos inherentes a las calles como los autos o el paso de la gente en principio. Para el caso de las sonoridades conocidas funciona para identificar el timbre de un teléfono o incluso el andar de una persona. 
Escucha semántica: utilizada para la interpretación de mensajes mediante un código conocido, para este caso de las calles del Centro Histórico, los pregones de los vendedores que aluden a cierto tipo de mercancías dan indicios muy claros sobre la actividad del lugar. No obstante ser voces desconocidas, los mensajes que transmiten tienen que ver directamente con la actividad específica de la calle: venta de artículos o periódicos, entre otros. Observar los eventos desde esta perspectiva será muy útil para reconocer los mensajes característicos del lugar. También es posible identificar mensajes en sonidos de ciertas características, como la señal sonora de algunos semáforos, que avisa sobre el cambio de luz.

Escucha reducida: atiende a la naturaleza del objeto sonoro schaefferiano, no a mensaje alguno ni cualquier otra relación expresiva. Hay sonidos que pueden diferenciar a una calle de otra, como la tapa de una coladera que al no asentar bien sobre su base genera un sonido característico al paso de los automóviles o la misma textura de las calles del Centro Histórico de la Ciudad de México, que reproducen un sonido diferente al de las demás calles al paso de las llantas de los vehículos.

En este sentido, atender al tipo de escucha utilizado para cada elemento ayudará a encontrar el peso específico de cada una de las partes. Es necesario aclarar: los tipos de escucha no serán utilizados de manera excluyente, pues un sonido puede ser estudiado por cada uno de ellos sin que el hecho represente un problema. Al contrario, combinar la información hará que encuentre un lugar idóneo en la clasificación generada.

\section{Resultados de la lectura de los registros (censo)}

Para el trabajo de censo se realizó un registro mediante una caminata por la calle Bolívar, desde la calle Regina y hasta la avenida Madero. Con dicho registro se tendrá una muestra de los sonidos de dicho trayecto que después se clasificaron según sus características, que se anotaron en las fichas diseñadas para tal efecto, aquí un ejemplo:

\subsection{Categorías e información}

- Escucha semántica: de qué se habla, información sobre actividades específicas representadas con la voz y demás códigos reconocibles como alarmas, señales sonoras de semáforos, silbatos de policía y sirenas, entre otros.

- Escucha causal: todo sonido que no pueda ser identificado será analizado en busca de sus causas y en caso de no poder identificarse pasará a la siguiente escucha.

Habrá sonidos cuya causa se identifique claramente, como el paso de automóviles, y también los habrá que no.

- Escucha reducida: al no poder identificar el origen del sonido, sólo se anotarán sus características acústicas en términos de repetición, intermitencia o incluso alguna idea sobre su origen.

- Unidad sonora: se plantea como el máximo reducto reconocible en términos tipológicos: el sonido de un automóvil es el tipo, mientras que cada uno de los elementos sonoros que lo componen como el alternador, las válvulas, ventilador, bomba de agua y demás, serán detalles que no se utilizarán en la clasificación. La unidad sonora es aquel reducto reconocible en términos generales y comunes de escucha.

- Conjunto: según la categoría anterior, el conjunto será en tráfico automotriz de las calles censadas. Dicha lógica se aplicará a todo el trabajo; el pregón de un vendedor específico será la unidad del conjunto "vendedores", como segundo ejemplo.

- Categoría paisajística: con base en las características de cada elemento censado, se justificará su categorización dentro de los componentes del paisaje sonoro que le posee. Por ejemplo, el pregón de un vendedor en un mercado será una marca sonora en un mercado, pero no en una calle por la que pasa de manera esporádica.

- Relación temporal: la sonoridad del Centro Histórico de la Ciudad de México presenta características que requieren analizar la permanencia de ciertos sonidos en períodos estacionales. Un ejemplo arquetípico lo constituyen los sonidos que componen el paisaje sonoro de las celebraciones del 15 de septiembre, que incluyen música popular característica, silbatos y pirotecnia entre otros. Por ello se especificarán no sólo el rango de 
Tabla 1. Ficha de clasificación de elementos del paisaje sonoro.

\begin{tabular}{|c|c|c|c|c|c|c|c|c|}
\hline \multirow[t]{2}{*}{ Relación de escucha } & \multirow[t]{2}{*}{ Elementos sonoros } & \multirow{2}{*}{\multicolumn{3}{|c|}{ Categoría paisajística }} & \multicolumn{4}{|c|}{ Relación temporal } \\
\hline & & & & & Estac & onal & Perma & nente \\
\hline $\begin{array}{l}\text { Tipología } \\
\text { de } \\
\text { escucha }\end{array}$ & Unidad Conjunto & Tonalidad & $\begin{array}{l}\text { Señal } \\
\text { sonora }\end{array}$ & $\begin{array}{l}\text { Huella } \\
\text { sonora }\end{array}$ & Mañana & Tarde & Mañana & Tarde \\
\hline $\begin{array}{l}\text { Escucha } \\
\text { semántica }\end{array}$ & & & & & & & & \\
\hline $\begin{array}{l}\text { Escucha } \\
\text { causal }\end{array}$ & & & & & & & & \\
\hline $\begin{array}{l}\text { Escucha } \\
\text { reducida }\end{array}$ & & & & & & & & \\
\hline $\begin{array}{l}\text { Evaluación } \\
\text { general }\end{array}$ & & & & & & & & \\
\hline
\end{tabular}

Fuente: elaboración propia.

horario en que aparecen sino también si asocia a alguna manifestación estacional cuando sea necesario. Por otra parte, para complementar dicha información, se marcará la presencia en términos de horario.

Se establece entonces a las 17 horas, pues es el que denota más la sonoridad ${ }^{5}$ de la calle seleccionada para el registro y posterior censo.

- Evaluación general: una vez clasificados de acuerdo con sus características, se propone determinar una evaluación global de cada elemento del paisaje. Independientemente de qué elemento sea, será posible asignarle una valoración de acuerdo con su grado de representación identitaria; así, según el ejemplo expuesto, a pesar de ser una marca sonora de la calle, el sonido del metrobús resulta molesto debido al sonido de su motor y el constante accionar de la bocina de sus unidades.

Con el propósito de corroborar la ficha de clasificación, se ha tomado como ejemplo el sonido del metrobús que circula por la calle República del Salvador y que ha pasado a formar parte de la identidad sonora de dicha calle, en el tramo comprendido entre el Eje Central Lázaro Cárdenas y la Av. 20 de noviembre.

Ejemplo:

\footnotetext{
${ }^{5}$ Se han realizado recorridos previos al registro a distintas horas del día con el fin de determinar el horario de mayor actividad en la calle con la que se ha trabajado.
}

La ficha de características servirá para marcar aspectos generales de cada elemento censado, mismos que posteriormente se analizarán con el fin de hacer una propuesta de categorías que pueda ser usada para censar los elementos de cualquier paisaje sonoro.

\section{Resultados de la lectura de los registros}

Tras haber realizado el registro y escucha de la calle seleccionada, fue necesario un recuento que acusó la totalidad de elementos paisajísticos que compusieron la muestra, además de detallar sus características y valoración en términos de identidad sonora. Al tener el registro es posible trabajar con el mismo tantas veces como sea necesario reproducirlo, con el fin de identificar los elementos y su categoría. Por ello no se recurrió a la escucha in situ, pues al ser varias capas de sonidos las que componen el paisaje sonoro habría sido imposible observarlas a un solo tiempo. Otra cuestión importante que cubre el registro es que contiene exactamente todo lo que se escuchó durante el mismo, pues los micrófonos no son selectivos, captan todo, no lo que a un humano pueda llamarle la atención en un momento dado. En este sentido apunta Jimena de Gortari:

El acercamiento al estudio del sonido basado en la eliminación de elementos desagradables dentro de un ambiente sonoro y el tratamiento de los sonidos como una señal a ser procesada y no 
Tabla 2. Ficha de clasificación de elementos del paisaje sonoro.

\begin{tabular}{|c|c|c|c|c|c|c|c|}
\hline \multirow[t]{2}{*}{ Relación de escucha } & \multirow[t]{2}{*}{ Elementos sonoros } & \multirow{2}{*}{\multicolumn{3}{|c|}{ Categoría paisajística }} & \multicolumn{3}{|c|}{ Relación temporal } \\
\hline & & & & & Estacional & \multicolumn{2}{|c|}{ Permamente } \\
\hline $\begin{array}{l}\text { Tipología } \\
\text { de } \\
\text { escucha }\end{array}$ & Unidad & Conjunto Tonalidad & $\begin{array}{l}\text { Señal } \\
\text { sonora }\end{array}$ & $\begin{array}{l}\text { Huella } \\
\text { sonora }\end{array}$ & Mañana Tarde & Mañana & Tarde \\
\hline \multicolumn{8}{|l|}{$\begin{array}{l}\text { Escucha } \\
\text { semántica }\end{array}$} \\
\hline $\begin{array}{l}\text { Escucha } \\
\text { causal }\end{array}$ & Metrobús & Tráfico & & $\begin{array}{l}\text { Identidad } \\
\text { de la } \\
\text { calle }\end{array}$ & & $\begin{array}{l}\text { Horario } \\
\text { de } \\
\text { servicio }\end{array}$ & $\begin{array}{l}\text { Horario } \\
\text { de } \\
\text { servicio }\end{array}$ \\
\hline \multicolumn{8}{|l|}{$\begin{array}{l}\text { Escucha } \\
\text { reducida }\end{array}$} \\
\hline $\begin{array}{l}\text { Evaluación } \\
\text { general }\end{array}$ & Huella sor & , característica de dic & a calle $\mathrm{d}$ & de abril de & 2012 durante los & rarios de & servicio. $L o-F i$ \\
\hline
\end{tabular}

Fuente: elaboración propia.

como información a ser analizada, es un tema en el que queda mucho por hacer. La supresión de factores negativos resulta un requerimiento elemental, pero también debe ser la generación de sonidos agradables o positivos, ${ }^{6}$ para construir ambientes sonoros más agradables. El análisis de ambas categorías ayudaría a mejorar los entornos urbanos. (de Gortari, 2013, p. 10)

En este sentido, un análisis que abarque demasiadas categorías podría volverse confuso, pues al incorporar las cualidades acústicas de los sonidos, por lo menos en términos de física, alejaría al presente trabajo de su intención primaria: un primer acercamiento a una clasificación con fines de estudio.

\section{Evaluación y conclusiones parciales sobre los elementos censados}

- Tráfico: uno de los elementos presente durante todo el registro, al ser la calle Bolívar una de las que atraviesa todo el Centro Histórico, mantiene un alto índice de

\footnotetext{
${ }^{6} \mathrm{~A}$ partir de este momento denominaremos sonidos positivos a todos aquellos sonidos que transmitan información. En este caso, es necesario aclarar que el valor positivo que propone la doctora Ludlow no es aplicable para el presente trabajo, pues en estricto sentido todos los sonidos transmiten información; desde el generado por el rodamiento de las llantas de los automóviles sobre la textura de la calle, hasta el vendedor ambulante que pregona su producto, los cantos de las aves, el generado por la acción de barrer la calle, todo sonido informa de algo. Por ello se ha propuesto para este caso que la valoración sea positiva solamente en el caso de que el sonido sea un signo identitario del lugar, es decir, su huella sonora.
}

circulación de automóviles y de transporte público, lo que hace más fuerte la carga sonora aportada por dicho elemento. Es evidentemente un sonido lo-fi pues irrumpe e incluso enmascara en cierta medida a los pocos elementos hi-fi que se han encontrado en el censo.

Por otra parte, es un sonido que es posible atenuar, por ejemplo, mediante el control de los sistemas de escape que han sido modificados para producir niveles de sonoridad más altos y que son muy comunes en unidades de transporte público. Otra alternativa es restringir el paso de transportes de mercancías a ciertos horarios, con el propósito de menguar el tránsito y su consiguiente producción sonora.

Como conclusión sobre éste, es un sonido que a la vez resulta huella sonora de una calle, en estricto sentido los automóviles son la razón de ser de las calles y en este caso se observa únicamente como elemento del censo, el matiz se dará entonces de acuerdo con los fines específicos del censo.

- Voces: es otro de los elementos con mayor presencia durante la mayor parte del registro. Las calles también permiten el tránsito de personas y en cierta medida también forman parte de sus elementos característicos. Al ser realizado en movimiento, no se pueden distinguir los temas de las conversaciones además ello no forma parte del objetivo del censo, a excepción de las voces de vendedores o personajes que pueden dar identidad 
a la calle. Las voces forman parte de los únicos dos elementos $h i$-fi que se han encontrado. Y es importante destacar que también se han clasificado como huella y marca sonoras, pues su presencia igual da cuenta del tránsito en las aceras, que forman parte de las calles.

En términos generales, es un elemento que no resulta molesto o que tenga intensidades altas cuando se trata de la gente que circula, a diferencia de las voces a través de sistemas de amplificación que se expondrán más adelante y cuya mediación tecnológica les ubica en otra categoría.

- Pájaros: el segundo elemento $h i-f i$ del registro. Un detalle importante es que éstos no fueron percibidos durante la caminata de registro, ya que fueron enmascarados por el resto de los componentes del paisaje que se hicieron presentes de manera simultánea. Dicho fenómeno es común en ejercicios de escucha, en los que se acusan más los elementos que se asocian comúnmente con las calles, como el sonido de los automóviles. Lo anterior hace importante recurrir a los registros de las caminatas, con el objeto de poder observarlos (escucharlos), las veces que sea necesario y no dejar fuera ningún elemento. Otra conclusión importante sobre este elemento es que los horarios matutino y vespertino permiten, al haber menos tránsito de automóviles, que su escucha sea más evidente, al no ser enmascarados por los motores de los transportes.

Como se dijo antes, los cantos de las aves son uno de los dos elementos $h i-f i$ registrados y su presencia es importante dentro del paisaje por esa circunstancia y porque sólo fue escuchado en dos ocasiones durante el trayecto, es decir, una mínima parte de la grabación.

- Altavoces: se encontró una alta presencia de altavoces amplificando tres tipos de sonidos con características particulares que se exponen a continuación.

Música. En este caso la música se divide en dos opciones: la primera corresponde a música en distintos locales comerciales y que se alcanza a escuchar en la calle, no tiene nivel alto pues se utiliza para ambientar la actividad principal de cada local; como restaurantes cantinas, y locales de ropa.
La segunda es demostración. Al ser una calle que en tres cuadras tiene una alta cantidad de locales de venta de instrumentos musicales y equipos de sonido, ya sea probando los mismos altavoces o instrumentos musicales. Los niveles son altos con el fin de demostrar las capacidades del equipo (como si un alto nivel de intensidad sonora denotara la calidad de los equipos). A diferencia del uso anterior, ya que incluso dichas pruebas sobrepasan los índices regulatorios de intensidad sonora, este tipo de pruebas sí debería ser controlado por la autoridad correspondiente.

Promoción. Es otro de los usos de los altavoces que está dirigido hacia afuera de los locales, y que reproduce grabaciones para atraer clientes. Por ello, están dirigidos directamente a las afueras del local por donde pasa la gente. En algunos casos los anuncios que reproducen tienen igualmente niveles altos y también pueden resultar molestos para los transeúntes y debieran ser regulados.

Sobre estos tres tipos de sonidos mediados por altavoces, también se puede concluir parcialmente, que de la misma manera que se les puede categorizar como huella sonora, se les puede clasificar como contaminación acústica, según la percepción particular de cada escucha.

- Bocina de automóvil: se encontraron tres eventos de este tipo en el recuento, aunque es una cuestión más circunstancial que el resto de los elementos, pues las condiciones de tráfico pueden variar incluso a la misma hora de distintos días. Para el caso analizado, el tráfico resultó tranquilo y los tres eventos censados lo denotan. Cabe destacar que el uso de las bocinas también está regulado, lo que no necesariamente indica que se respete o sancione.

- Pregón: es uno de los elementos que se menciona como componente histórico de la sonoridad de las calles del Centro Histórico de la Ciudad de México a principios del siglo XX. En este caso, el vendedor de nieves no le "pertenece" a una sola calle, pues es común que distintos tipos de vendedores recorran varias calles anunciando sus productos. Aunque también existen vendedores-pregoneros con presencia fija en las calles, 
este no es el caso. La importancia de este elemento es que representa una conexión entre el paisaje sonoro del mismo lugar en dos tiempos e incluso un análisis sobre este elemento pudiera ubicarlo como huella sonora de un territorio más amplio.

- Alarma de reloj: la esquina de Bolívar y Venustiano Carranza ubica un monumento donado por la comunidad otomana a México. Dicho monumento está coronado por un reloj que hace sonar una campana cada media hora, en los minutos 0 y 30 . Es evidente que ese sonido es la marca sonora de dicha esquina, y también una de las marcas sonoras de la calle Bolívar.

- Carro metálico: también son comunes los "diablitos" y algunos otros tipos de transportes de mercancías impulsados por humanos. Éste se trató de un carro metálico que rozaba sus componentes al rodar vacío. También son comunes en varias calles.

- Músico: el músico itinerante con acordeón es el mismo caso del pregón del vendedor de nieves.

- Utensilios de cocina: al paso por la entrada de un restaurante, se escuchó el sonido arquetípico de los cubiertos golpeando sobre los platos al utilizarlos.

- Indicador sonoro de semáforo: en la esquina final del recorrido, Avenida Madero y Bolívar, el semáforo está equipado con señal sonora que marca el tiempo del alto para los autos que circulan sobre Bolívar. Un dato adicional es que la avenida Madero ya sólo permite el tránsito de personas y un gran número de ellas circulan y cruzan dicha esquina por lo que la señal sonora para invidentes resulta muy útil, incluso si se puede ver, pues señala el tiempo próximo al fin del paso de los peatones. Esta alarma, también constituye la marca sonora de dicha esquina y por consiguiente una de las dos marcas sonoras encontradas en el tramo de la calle que ha sido objeto del censo.

\section{Conclusiones}

Como puede observarse, la descripción y relación de cada uno los elementos que conforman el paisaje registrado y censado, abre un conjunto de posibilidades para el estudio sobre sus orígenes, causas, capacidades expresivas y/o identitarias, antigüedad y muchas más si esta información se cruza, por ejemplo, con regulaciones sobre los niveles sonoros de los lugares en que se ha realizado el censo, con fines de estudios sobre ecología acústica (Wrightson, 2000). Esta propuesta metodológica y de clasificación se propone como un primer acercamiento para dichas tareas, cuyo interés en principio ha sido con fines de preservación de aquellos sonidos que se han denotado como huellas sonoras del paisaje registrado.

Para ejemplificar otro matiz que permite redireccionar de acuerdo con intereses particulares de búsqueda en la realización de un censo sonoro, se retoma el ejemplo dispuesto en la ficha de ejemplo (tabla 2), pues la búsqueda de contaminación sonora dejaría de prestar importancia al grado de representatividad de dicho elemento como huella sonora, para ubicarlo en otra categoría que acuse sus características más en torno a la contaminación sonora presente en el paisaje. El interés particular de cada búsqueda será el que determine las características de cada análisis. El presentado es meramente descriptivo de los elementos que conforman el paisaje registrado, para ubicarlos en cada una de las categorías schaferianas, mismas que serán base para plantear las características particulares de otras búsquedas específicas, como las que también se han mencionado en el presente texto.

\section{Referencias}

De Gortari, J. (2013) Guía sonora para una ciudad. México: Juan Pablos Editor.

Carles, J. y Palmese, C. (s/f) Identidad sonora urbana. (Blog) Estudio de Música Electroacústica. Recuperado el 12 de abril de 2010, de https://bit.ly/2nKoS4Y

Chion, M.(1999). El sonido. Madrid: Paidós.

Schafer, M. (1977) The Tuning of the World: Toward a Theory of Soundscape Design. EUA: University of Pennsylvania Press.

Schafer, M. (2005). Hacia una educación sonora. México: Consejo Nacional para la Cultura y las Artes.

Schaeffer, P. (1966) Traité des objets musicaux. Paris: Ed. Seuil

Wrightson, K. (2000). An introduction to acoustic ecology. En Soundscape. The Journal of Acoustic Ecology 1 (1). 
Tabla 3. Tabla de resultados del censo.

\begin{tabular}{|c|c|c|c|c|c|c|}
\hline Sonido & Tonalidad & Señal sonora & Huella sonora & Lo-fi & Hi-fi & Observaciones \\
\hline Tráfico & & $\mathrm{X}$ & $\mathrm{X}$ & $\mathrm{X}$ & & Constante durante todo el registro \\
\hline Voces & & $\mathrm{X}$ & $\mathrm{X}$ & & $\mathrm{X}$ & Constante durante todo el registro \\
\hline Pájaros & & $\mathrm{X}$ & & & $\mathrm{X}$ & $\begin{array}{l}\text { Sólo al inicio del registro, en un área } \\
\text { con árboles }\end{array}$ \\
\hline Pájaros & & $\mathrm{X}$ & & $\mathrm{X}$ & & Lejanos, posiblemente los primeros \\
\hline Altavoz & & $\mathrm{X}$ & & $\mathrm{X}$ & & Desde un local comercial, música \\
\hline Altavoz & & $\mathrm{X}$ & & $\mathrm{X}$ & & Desde un local comercial, música \\
\hline Altavoz & & $\mathrm{X}$ & & $\mathrm{X}$ & & $\begin{array}{l}\text { Desde un local comercial, sonido de } \\
\text { un bajo }\end{array}$ \\
\hline Altavoz & & $\mathrm{X}$ & & $\mathrm{X}$ & & Desde un local comercial, música \\
\hline Altavoz & & $\mathrm{X}$ & & $\mathrm{X}$ & & Desde un local comercial, música \\
\hline Bocina & & $\mathrm{X}$ & & $\mathrm{X}$ & & Bocina de automóvil \\
\hline Altavoz & & $\mathrm{X}$ & & $\mathrm{X}$ & & Desde un local comercial, música \\
\hline Altavoz & & $\mathrm{X}$ & & $\mathrm{X}$ & & Desde un local comercial, música \\
\hline Pregón & & $\mathrm{X}$ & & & $\mathrm{X}$ & Vendedor de nieves itinerante \\
\hline Altavoz & & $\mathrm{X}$ & & $\mathrm{X}$ & & Desde un local comercial, música \\
\hline Altavoz & & $\mathrm{X}$ & & $\mathrm{X}$ & & Desde un local comercial, música \\
\hline Altavoz & & $\mathrm{X}$ & & $\mathrm{X}$ & & Desde un local comercial, música \\
\hline Altavoz & & $\mathrm{X}$ & & $\mathrm{X}$ & & Desde un local comercial, música \\
\hline Alarma de reloj & & & $\mathrm{X}$ & $\bar{X}$ & & $\begin{array}{l}\text { Señal horaria del reloj situado en } \\
\text { la esquina de Bolívar y Venustiano } \\
\text { Carranza }\end{array}$ \\
\hline Altavoz & & $\mathrm{X}$ & & $\mathrm{X}$ & & Desde un local comercial, música \\
\hline Altavoz & & $\mathrm{X}$ & & $\mathrm{X}$ & & Desde un local comercial, música \\
\hline Altavoz & & $\mathrm{X}$ & & $\mathrm{X}$ & & Desde un local comercial, música \\
\hline Altavoz & & $\mathrm{X}$ & & $\mathrm{X}$ & & Desde un local comercial, música \\
\hline Altavoz & & $\mathrm{X}$ & & $\mathrm{X}$ & & Desde un local comercial, música \\
\hline Bocina & & $\mathrm{X}$ & & $\mathrm{X}$ & & Bocina de automóvil \\
\hline Altavoz & & $\mathrm{X}$ & & $\bar{X}$ & & Desde un local comercial, música \\
\hline Bocina & & $\mathrm{X}$ & & $\bar{X}$ & & Bocina de automóvil \\
\hline Bocina & & $\mathrm{X}$ & & $\mathrm{X}$ & & Bocina de automóvil \\
\hline Carro metálico & & $\mathrm{X}$ & & $\mathrm{X}$ & & $\begin{array}{l}\text { Carro de empujar para transporte de } \\
\text { objetos }\end{array}$ \\
\hline Bocina & & $\mathrm{X}$ & & $\mathrm{X}$ & & Bocina de automóvil \\
\hline Bocina & & $\mathrm{X}$ & & $\mathrm{X}$ & & Bocina de automóvil \\
\hline Altavoz & & $\mathrm{X}$ & & $\mathrm{X}$ & & Desde un local comercial, música \\
\hline Músico & & $\mathrm{X}$ & & $\mathrm{X}$ & & Músico callejero con acordeón \\
\hline Golpes de objetos & & $\mathrm{X}$ & & $\mathrm{X}$ & & Sin identificar su origen \\
\hline $\begin{array}{l}\text { Golpes de utensilios } \\
\text { de cocina }\end{array}$ & & $\mathrm{X}$ & & $\mathrm{X}$ & & $\begin{array}{l}\text { Golpes de utensilios de cocina } \\
\text { chocando entre ellos }\end{array}$ \\
\hline $\begin{array}{l}\text { Indicador sonoro de } \\
\text { semáforo }\end{array}$ & & & $\mathrm{X}$ & $\mathrm{X}$ & & $\begin{array}{l}\text { Indicador sonoro de cambio de luz } \\
\text { en el semáforo de Madero y Bolívar }\end{array}$ \\
\hline Altavoz & & $\mathrm{X}$ & & $\mathrm{X}$ & & Desde un local comercial, música \\
\hline
\end{tabular}

Fuente: elaboración propia. 